\title{
A cautionary tale of failure
}

\author{
My Imaginary Illness: A Journey into \\ Uncertainty and Prejudice in Medical \\ Diagnosis \\ Chloë G.K. Atkins \\ Cornell University Press; 2010
}

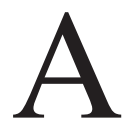
t the age of 20, Chloë Atkins began experiencing recurrent bouts of paralysis, loss of bladder and bowel control and intermittently the inability to breathe on her own. These episodes were associated with great physical and mental suffering and severely affected her social and professional life over the next two decades.

Perhaps the most difficult part of her illness, though, was that most of the physicians involved in her care did not believe that there was anything physically wrong with her. Instead of inspiring sympathy and compassion, she became the object of derision, scorn and sometimes overt hostility among the people she relied upon when ill. Because her symptoms and test results did not conform neatly to any conventionally recognized form of disease, she was repeatedly told she was not sick at all, but that she was pulling off "an elaborate scam," malingering or suffering from a psychiatric

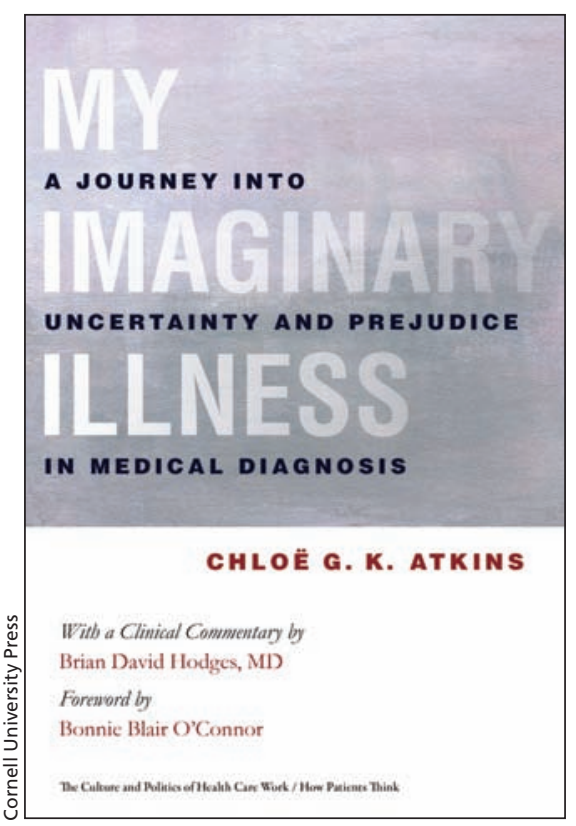

When one physician told Atkins that there was nothing wrong with her, she asked "How was it that I was not breathing or conscious when I arrived in the ER?" His response was that the monitors must not have been read correctly. On another occasion, when she requested that the medications that had brought about a certain improvement in her condition be restarted, Atkins was told by a doctor that "We are not giving you any medications. You're not sick

\section{"If I had no diagnosis then my symptoms meant nothing."}

disorder. Seeking care in medical centres far from home, she was initially treated with empathy and dedication by the new providers. However, once her medical records (in which the previous teams' suspicions were documented) arrived, the providers' demeanor quickly changed, and she again found herself battling skepticism and mistrust.
... You may be able to convince others, but you will not convince us!"

Ultimately given a diagnosis of an atypical form of myasthenia gravis, Atkins writes that "the uncertainty of the diagnosis, along with the doctors' insistence that my poor health was my own fault, made me distrust myself." Continuing along this line elsewhere, she writes that "Most people would be happy to discover that 'there's nothing wrong with you.' On the one hand, I wanted to be well regardless of the diagnosis. On the other, I wanted to have a specific disease ... If I had no diagnosis then my symptoms meant nothing - which in this case reinforced the view that I was a nutcase, full stop ... Emotionally, I wanted to be validated." These lines resonated with this reader, reminding me of how valuable it was when, after suffering from prolonged lower back pain, two herniated discs were discovered by magnetic resonance imaging. While not changing the management, treatment or duration of symptoms, it did substantiate to some degree the debilitating pain being experienced and "prove" that it was real.

Reading this autobiography, it is possible to see things both from her perspective and from that of her physicians. What she endured over the 20 years of her illness is heartbreaking and difficult to dismiss, and leaves the reader hoping never to be treated, or to treat another in this way. And yet, the inconsistency of her symptoms with her physical examination and the inconclusive or even normal laboratory tests, the seeking of care from multiple providers ("doctor shopping" in medical parlance), the unclear circumstances of her estrangement from her immediate family and her deliberate contamination of a central IV line all of these factors would raise questions in any physician's mind as to whether some darker explanation for her complaints might be present.

This reader could not help but wonder whether he, in a similar situation, would have responded differently (though he certainly hopes so). Every physician has cared for difficult patients who have not gotten better despite his or her best efforts. It is a frustrating experience that can adversely affect 
one's self-esteem, even if the physician understands that the practice of medicine is about helping the patient, not about boosting his or her own ego.

Atkins was still ill at the time she completed her book, but writes: "Overall, we experience much less stress as a family and as a couple knowing that I have access to physicians who treat me with respect, who take my symptoms seriously and respond quickly to anything that may arise."
My Imaginary Illness explores many aspects of the patient-physician relationship: the importance of good communication; openness to what the patient is experiencing; the limitations of evidence-based medicine, especially as it pertains to patients whose symptoms fall outside the neatly packaged diagnostic criteria currently in vogue; the imbalance of power between patient and physicians and how that behooves physicians to relate to patients. It is a heartbreaking story, and one that should be read by every health care provider as a cautionary tale of how physicians (and nurses) can so utterly fail those most in need of their help.

\section{Dennis Rosen MD}

Division of Respiratory Diseases

Children's Hospital Boston

Harvard Medical School

Boston, Mass.

CMAJ 2011. DOI:10.1503/cmaj.110418 